\title{
Numerical Simulation of Solitary Wave Induced Flow Motion around a Permeable Submerged Breakwater
}

\author{
Jisheng Zhang, ${ }^{1,2}$ Jinhai Zheng, ${ }^{1,2}$ \\ Dong-Sheng Jeng, ${ }^{3}$ and Gang Wang ${ }^{1,2}$ \\ ${ }^{1}$ State Key Laboratory of Hydrology-Water Resources and Hydraulic Engineering, \\ Hohai University, Nanjing 210098, China \\ ${ }^{2}$ College of Harbor, Coastal, and Offshore Engineering, Hohai University, Nanjing 210098, China \\ ${ }^{3}$ Division of Civil Engineering, University of Dundee, Dundee DD1 4HN, UK
}

Correspondence should be addressed to Jisheng Zhang, jszhang@hhu.edu.cn

Received 29 July 2012; Revised 16 October 2012; Accepted 17 October 2012

Academic Editor: Michael Meylan

Copyright (C) 2012 Jisheng Zhang et al. This is an open access article distributed under the Creative Commons Attribution License, which permits unrestricted use, distribution, and reproduction in any medium, provided the original work is properly cited.

\begin{abstract}
This paper presents a numerical model for the simulation of solitary wave transformation around a permeable submerged breakwater. The wave-structure interaction is obtained by solving the Volume-Averaged Reynolds-Averaged Navier-Stokes governing equations (VARANS) and volume of fluid (VOF) theory. This model is applied to understand the effects of porosity, equivalent mean diameter of porous media, structure height, and structure width on the propagation of a solitary wave in the vicinity of a permeable submerged structure. The results show that solitary wave propagation around a permeable breakwater is essentially different from that around impermeable one. It is also found that the structure porosity has more impact than equivalent mean diameter on the wave transformation and flow structure. After interacting with the higher structure, the wave has smaller wave height behind the structure with a lower travelling speed. When the wave propagates over the breakwater with longer width, the wave travelling speed is obviously reduced with more wave energy dissipated inside porous structure.
\end{abstract}

\section{Introduction}

Breakwaters have been extensively used for the near-shore protection by the coastal engineers, and, in composition, it can be impermeable or permeable. One of the main advantages for applying breakwaters is to dissipate and/or reflect the energy of the incident waves and consequently prevent erosion in near-shore regions [1]. In the recent years, the permeable breakwater has become increasingly popular as additional wave energy can be 
dissipated due to the flow friction within the porous media [2-4]. As one can expect, the flow motion around a permeable breakwater may be essentially different from that around an impermeable solid surface. Ocean waves travel through the porous media and may significantly affect the dissipation rate of wave energy $[5,6]$.

Many studies have been carried out by using laboratory experiments to investigate the interaction of incident wave and permeable structure. For example, Huang and Chao [7] experimentally studied the reflection and transmission of a small-amplitude water wave by a permeable breakwater in an infinitely long channel, and they found that the reflected wave is greater while the transmitted wave is less for waves of higher frequency with thicker and less permeable breakwaters. Losada et al. [8] carried out a set of experiments to investigate the monochromatic wave propagation over a submerged impermeable or porous step, and concluded that wave energy dissipation due to the porous material is the main mechanism controlling dissipation in the absence of wave breaking. For the breaking wave transmission over submerged permeable breakwater, Kobayashi et al. [9] found that the energy dissipation of wave train is mainly due to the wave breaking and the porous flow resistance inside the marine structure. All previous research measurements show that the degree of wave-structure interaction and its resulting energy dissipation highly depend on the incident wave conditions and structural parameters $[10,11]$.

Recently, several mathematical models based on the Navier-Stokes (NS) equations have been developed to study this topic, such as the model applied by Nakayama and Kuwahara [12], Liu et al. [13], Pedras and de Lemos [14], Hsu et al. [15], Chandesris et al. [16], and Karim et al. [17]. Among these models, there are two main approaches to consider the effect of porous media on wave motion in governing equations. One is to insert geometric properties and fluid resistance of porous media to the NS equations and the other is to use volume-averaging theory (applying a volume-averaging operator over a representative elementary volume to the NS equations). As discussed by Huang et al. [5], the NS-type models have shown great abilities in modelling the interaction of wave and permeable structure, overcoming the drawbacks of the other models based on mildslope equations [18], finite-amplitude shallow-water wave equations [19], or Boussinesqtype equations [20].

It is well acknowledged that solitary wave transformation around marine breakwaters is a critical problem when evaluating the effects produced by tsunami waves in coastal areas [21]. This study aims to understand the effects of physical properties (porosity, equivalent mean diameter, structure height, and structure width) of permeable breakwater on the wavestructure interactions subjected to a solitary wave. The governing equations, together with boundary conditions and numerical methods, are briefly introduced. Then, this model is applied to investigate the effects of physical properties of structure on the water elevation and velocity distribution in the vicinity of breakwater. The breakwater with impermeable solid surface is considered as a special case with zero porosity, and the simulation results from this special case is taken as benchmark for comparison.

\section{Model Description}

A vertical two-dimensional model first presented by Hsu et al. [15] is used for the wavestructure interactions, solving the Volume-Averaged Reynolds-Averaged Navier-Stokes (VARANS) equations for the outer and inner flows of permeable breakwater. 


\subsection{Governing Equations}

The VARANS for the flow motion due to wave-structure interactions can be expressed as [15]:

$$
\begin{gathered}
\frac{\partial\left\langle\bar{u}_{i}\right\rangle}{\partial x_{i}}=0, \\
\frac{\partial\left\langle\bar{u}_{i}\right\rangle}{\partial t}+\frac{\left\langle\bar{u}_{j}\right\rangle}{n\left(1+c_{A}\right)} \frac{\partial\left\langle\bar{u}_{i}\right\rangle}{\partial x_{j}}= \\
\frac{1}{1+c_{A}}\left[-\frac{n}{\rho} \frac{\partial\langle\bar{P}\rangle^{f}}{\partial x_{i}}-\frac{\partial\left\langle\overline{u_{i}^{\prime} u_{j}^{\prime}}\right\rangle}{\partial x_{j}}+\frac{1}{\rho} \frac{\partial\left\langle\bar{\tau}_{i j}\right\rangle}{\partial x_{j}}+n g_{i}\right] \\
-\frac{1}{1+c_{A}}\left[\frac{\alpha(1-n)^{2}}{n^{2} D_{50}^{2}}+\frac{\beta(1-n)}{n^{2} D_{50}} \sqrt{\left\langle\bar{u}_{1}\right\rangle^{2}+\left\langle\bar{u}_{2}\right\rangle^{2}}\right]\left\langle\bar{u}_{i}\right\rangle,
\end{gathered}
$$

where $u_{i}$ is the flow velocity, $x_{i}$ is the Cartesian coordinate, $t$ is time, $\rho$ is water density, $P$ is pressure, $\tau_{i j}$ is viscous stress tensor of the mean flow, $g_{i}$ is acceleration due to gravity, and $n$ and $D_{50}$ are the porosity and the equivalent mean diameter of the porous material. $c_{A}$ denotes the added mass coefficient, calculated from $c_{A}=0.34((1-n) / n) . \alpha=200$ and $\beta=1.1$ are empirical coefficients associated with the linear and nonlinear drag force, respectively [22]. The influence of turbulence fluctuation on the mean flow, denoted as $\left\langle u_{i}^{\prime} u_{j}^{\prime}\right\rangle$, is obtained by solving the modified $k-\varepsilon$ turbulence model where $k$ is the kinetic energy and $\varepsilon$ is the dissipation rate of kinetic energy [23]. The over-bar represents the ensemble average and the prime denotes turbulent fluctuations with respect to the ensemble mean. The " \langle\rangle ," Darcy's volume-averaging operator, is defined as follows:

$$
\langle a\rangle=\frac{1}{V} \int_{V_{f}} a d V
$$

where $V$ is the total averaging volume, and $V_{f}$ is the portion of $V$ that is occupied by the fluid. The " \langle\rangle$^{f}$ " is the intrinsic-averaging operator, which is defined as follows:

$$
\langle a\rangle^{f}=\frac{1}{V_{f}} \int_{V_{f}} a d V
$$

The relationship between Darcy's volume-averaging operator and the intrinsic volume averaging is

$$
\langle a\rangle=n\langle a\rangle^{f}
$$

\subsection{Numerical Method}

In the model, finite difference solutions to the VARANS for the mean flow field and the modified $k-\varepsilon$ turbulence model for the turbulent field are obtained on a nonuniform mesh. A two-step projection method is adopted for the mean flow solutions, aided by the incomplete Cholesky conjugate gradient technique solving the Poisson equation for the mean pressure 
field. The volume of fluid (VOF) method proposed by Hirt and Nichols [24] is applied to track water free-surface locations. The idea of VOF is to define a function of $F$ to represent the fractional volume of water fluid. $F=1$ indicates that the cell is full of water, while $F=0$ corresponds to a cell fully occupied by air. Cells with a value of $0<F<1$ contain a water free surface, and the piecewise linear interface calculation (PLIC) method of Rider and Kothe [25] is used to reconstruct air-water interface. The algorithm consists of two steps: a planar reconstruction of air-water interfaces within a cell; then a geometric calculation of volume fluxes of air and water cross-cell faces. In the numerical simulation, both air and water are solved.

Appropriate boundary conditions need to be specified in the simulation. For the mean flow field, no-slip boundary condition is imposed on the sea floor surface, and the zerostress condition is adopted on the mean free surface by neglecting the effect of air flow. For the turbulence field, the log-law distribution of mean tangential velocity in the turbulent boundary layer is applied in the grid point next to sea floor, and the zero-gradient boundary conditions are imposed for both $k$ and $\varepsilon$ on the free surface. The damping zones are located at two vertical boundaries far away from the concerned region. The detailed implementations of boundary conditions are referred to $[15,23]$. To obtain computational stability, the time interval $(\Delta t)$ is automatically adjusted at each time step to satisfy the Cournat-FriedrichsLewy condition and the diffusive limit condition [13].

\section{Numerical Results and Discussion}

\subsection{Numerical Experiments}

A serial of numerical experiments have been performed to investigate the effects of porosity $n$ and equivalent mean diameter $D_{50}$ on the solitary wave-structure interactions. As shown in Figure 1, the computational domain has $L=450 \mathrm{~m}$ in $x$-direction and $H=7 \mathrm{~m}$ in $z$-direction. The origin of the Cartesian coordinate is located at the left subcorner of the rectangular permeable submerged breakwater which has $w=50 \mathrm{~m}$ and $h=3 \mathrm{~m}$. The numerical cases with different $n, D_{50}$ of porous material, structure height $h$ and width $w$ are listed in the Table 1 . The permeability $K_{p}$ of porous structure is estimated from $n$ and $D_{50}$ in the form of $D_{50}^{2} n^{3} /\left(\alpha(1-n)^{2}\right)$ [19]. Solitary wave is generated by using internal wave-maker method of [22] on $x=-200 \mathrm{~m}$ (right hand side of permeable submerged structure) at $t(g / d)^{0.5}=0 \mathrm{~s}$, with a still water depth $d=5.0 \mathrm{~m}$ and wave height $H_{w}=0.75 \mathrm{~m}$. The area of source region in which the source term wave-maker is acting is predefined and keeps constant during the simulation. As recommended by [22], the source region has a height of $10 \%$ of water depth $(0.65 d \sim 0.75 d)$ and a width of $5 \%$ of wavelength. Different mesh sizes are tested, and a mesh with $\Delta x=0.25 \mathrm{~m}$ and $\Delta z=0.05 \mathrm{~m}$ is adopted in this study.

\subsection{Impact on Wave Transformation}

The transformation of a solitary wave travelling over a permeable submerged breakwater with $n=0.2$ and $D_{50}=0.05 \mathrm{~m}$ is illustrated in Figure 2. The result shows that the structure with $w=10 \mathrm{~d}$ and $h=0.6 \mathrm{~d}$ significantly affects its adjacent wave propagation. Wave distortion takes place when the wave is passing over the breakwater, which is mainly due to the nonlinear effect caused by the breakwater. The interaction between solitary wave and 


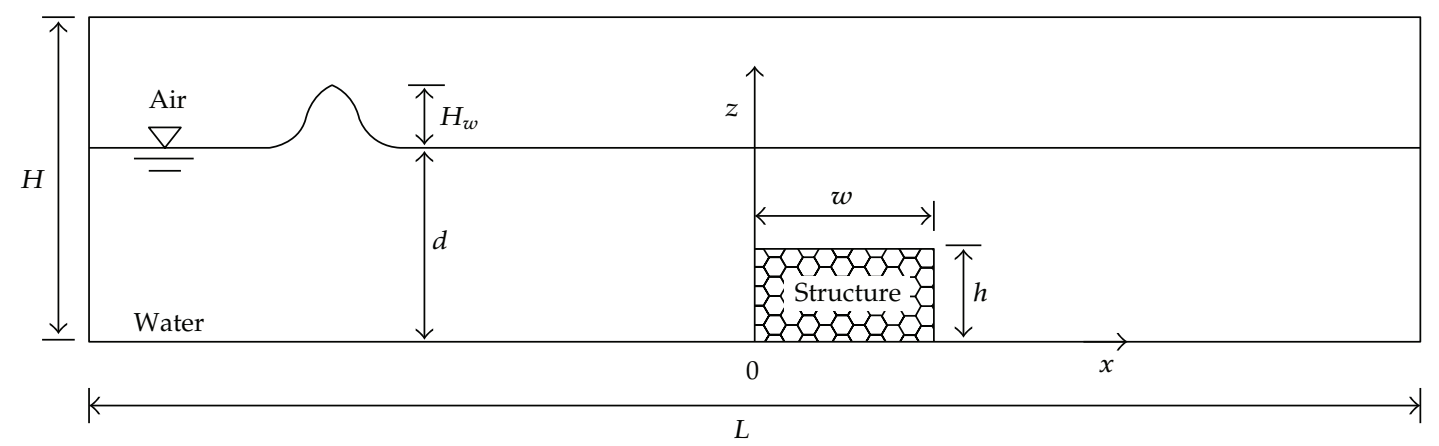

Figure 1: A sketch of computational domain.

Table 1: Numerical cases with different breakwater parameters.

\begin{tabular}{lccccc}
\hline Case no. & $\begin{array}{c}\text { Porosity } \\
(n)\end{array}$ & $\begin{array}{c}\text { Equivalent mean } \\
\text { diameter }\left(D_{50}\right)\end{array}$ & $\begin{array}{c}\text { Permeability } \\
\left(K_{p}\right)\end{array}$ & $\begin{array}{c}\text { Height } \\
(h)\end{array}$ & $\begin{array}{c}\text { Width } \\
(w)\end{array}$ \\
\hline$(1)$ & 0 & - & - & $3.0 \mathrm{~m}$ & $50.0 \mathrm{~m}$ \\
$(2)$ & 0.2 & $0.05 \mathrm{~m}$ & $1.5625 \times 10^{-7} \mathrm{~m}^{2}$ & $3.0 \mathrm{~m}$ & $50.0 \mathrm{~m}$ \\
$(3)$ & 0.4 & $0.05 \mathrm{~m}$ & $2.2222 \times 10^{-6} \mathrm{~m}^{2}$ & $3.0 \mathrm{~m}$ & $50.0 \mathrm{~m}$ \\
$(4)$ & 0.6 & $0.05 \mathrm{~m}$ & $1.6875 \times 10^{-5} \mathrm{~m}^{2}$ & $3.0 \mathrm{~m}$ & $50.0 \mathrm{~m}$ \\
$(5)$ & 0.4 & $0.03 \mathrm{~m}$ & $8.0000 \times 10^{-7} \mathrm{~m}^{2}$ & $3.0 \mathrm{~m}$ & $50.0 \mathrm{~m}$ \\
$(6)$ & 0.4 & $0.07 \mathrm{~m}$ & $4.3556 \times 10^{-6} \mathrm{~m}^{2}$ & $3.0 \mathrm{~m}$ & $50.0 \mathrm{~m}$ \\
$(7)$ & 0.4 & $0.15 \mathrm{~m}$ & $2.0000 \times 10^{-5} \mathrm{~m}^{2}$ & $3.0 \mathrm{~m}$ & $50.0 \mathrm{~m}$ \\
$(8)$ & 0.4 & $0.05 \mathrm{~m}$ & $2.2222 \times 10^{-6} \mathrm{~m}^{2}$ & $2.0 \mathrm{~m}$ & $50.0 \mathrm{~m}$ \\
$(9)$ & 0.4 & $0.05 \mathrm{~m}$ & $2.2222 \times 10^{-6} \mathrm{~m}^{2}$ & $4.0 \mathrm{~m}$ & $50.0 \mathrm{~m}$ \\
$(10)$ & 0.4 & $0.05 \mathrm{~m}$ & $2.2222 \times 10^{-6} \mathrm{~m}^{2}$ & $3.0 \mathrm{~m}$ & $40.0 \mathrm{~m}$ \\
$(11)$ & 0.4 & $0.05 \mathrm{~m}$ & $2.2222 \times 10^{-6} \mathrm{~m}^{2}$ & $3.0 \mathrm{~m}$ & $30.0 \mathrm{~m}$ \\
\hline
\end{tabular}

breakwater with small width, such as $w=1 d$ was studied by Huang et al. [5], and no obvious wave distortion was found.

Figure 3 shows the effect of structural porosity on wave transformation at different time instances, with the case 1 of an impermeable breakwater being the benchmark for comparison. The porosity parameter has no impact on the wave propagation until the wave crest reaches the breakwater at about $t(g / d)^{0.5}=49$. After that, the friction of porous media starts to play an important role in dissipating wave energy. Weaker wave deformation and less wave height occur for the breakwater with large porosity (leading to higher permeability), as more wave energy is dissipated due to the friction of porous media when structural porosity increases from 0 to 0.6 (see Figures 3(b)-3(d)). Due to the construction of breakwater, the cross-section space for passing the solitary wave is partly blocked. As a result, the wave height can be largely increased when the solitary wave is travelling over the structure. For example, at time $t(g / d)^{0.5}=49$, an increase of $20 \%$ of wave height is identified in the case 1. After passing the permeable breakwater, the wave height becomes smaller than the generated due to wave dissipation in all cases. The effect of $D_{50}$ is also studied, and the results indicate that the variation in wave transformation progress is slight with an increase of $D_{50}$ from $0.03 \mathrm{~m}$ to $0.15 \mathrm{~m}$. 


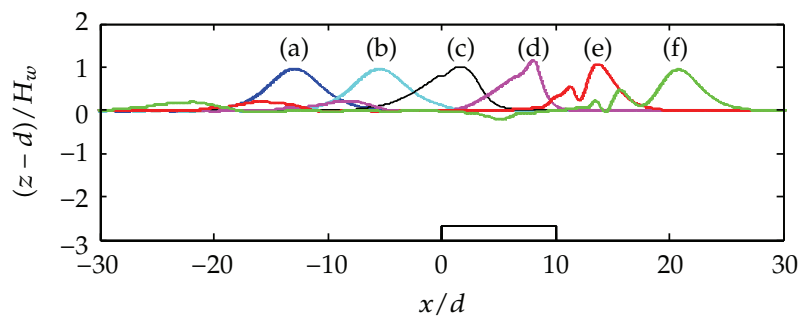

Figure 2: Transformation of a solitary wave travelling over a submerged breakwater with $n=0.2$ and $D_{50}=$ $0.05 \mathrm{~m}$ at different time levels: (a) $t(g / d)^{0.5}=35$, (b) $t(g / d)^{0.5}=42$, (c) $t(g / d)^{0.5}=49$, (d) $t(g / d)^{0.5}=56$, (e) $t(g / d)^{0.5}=63$, and (f) $t(g / d)^{0.5}=70$.

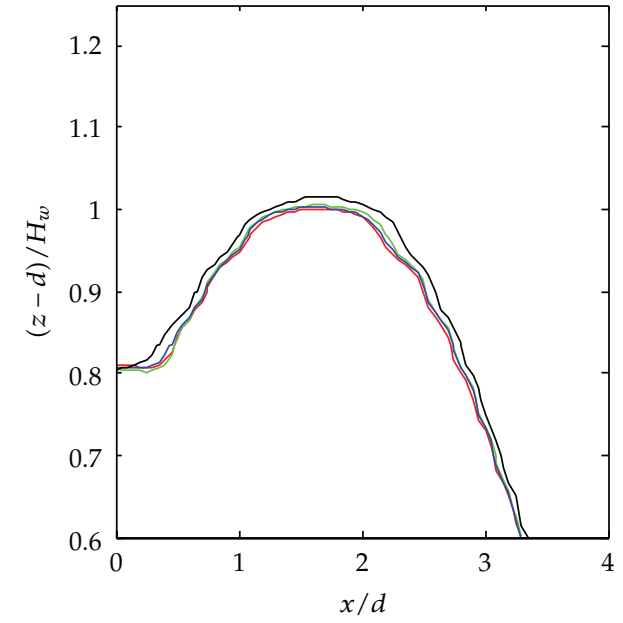

(a) $t(g / d)^{0.5}=49$

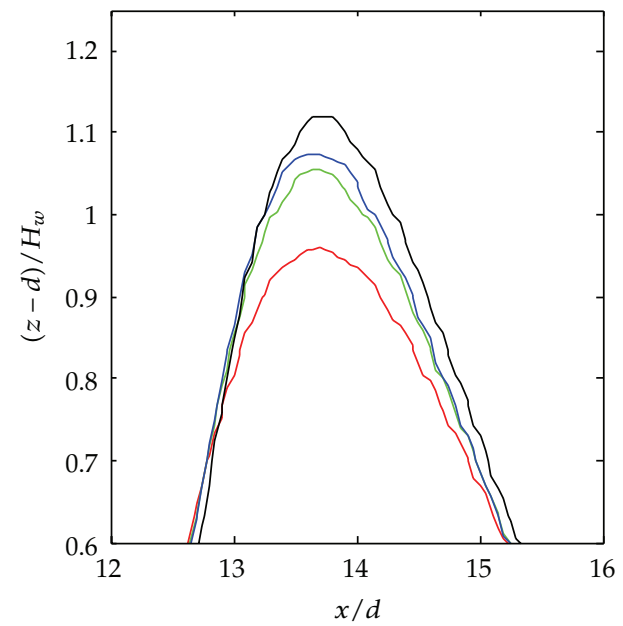

(c) $t(g / d)^{0.5}=63$

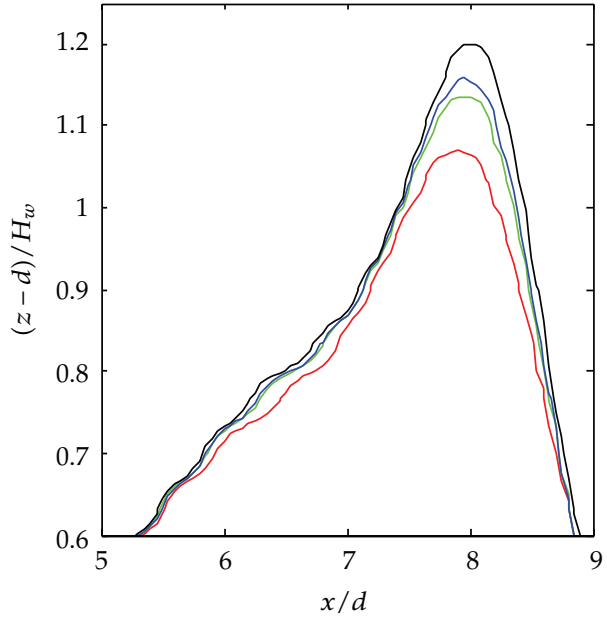

(b) $t(g / d)^{0.5}=56$

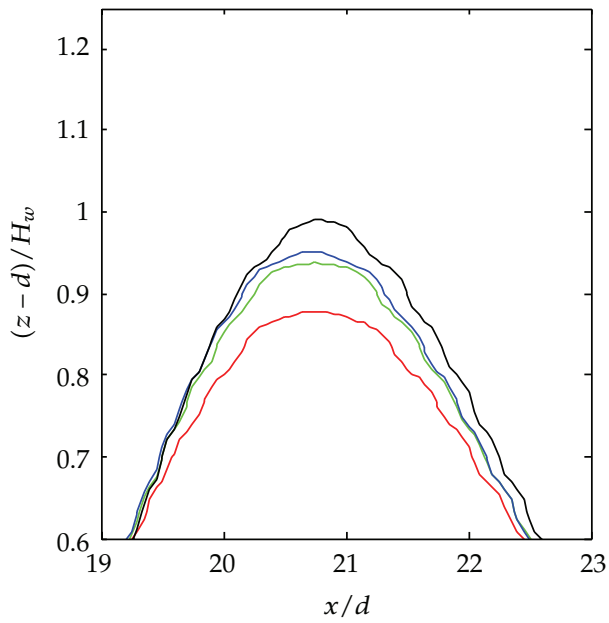

(d) $t(g / d)^{0.5}=70$

Figure 3: The effect of structural porosity on wave transformation for porosity $n=0$ black curve, $n=0.2$ blue curve, $n=0.4$ green curve, and $n=0.6$ red curve. 


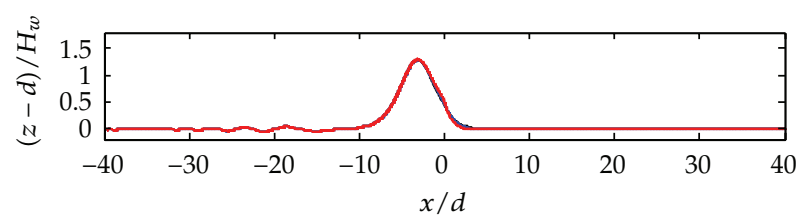

(a)

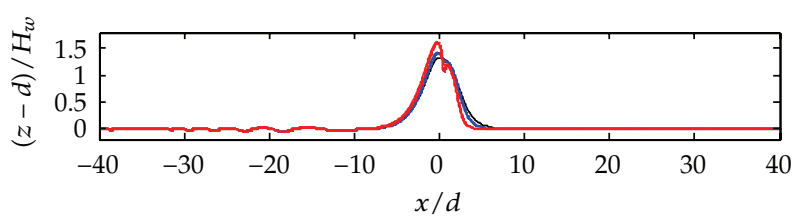

(b)

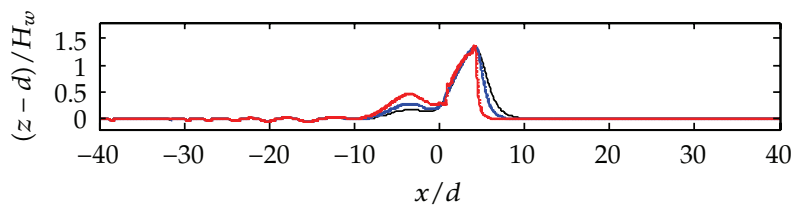

(c)

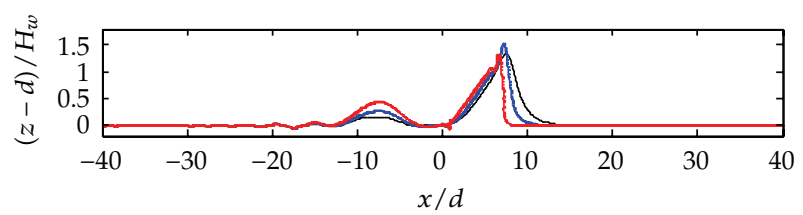

(d)

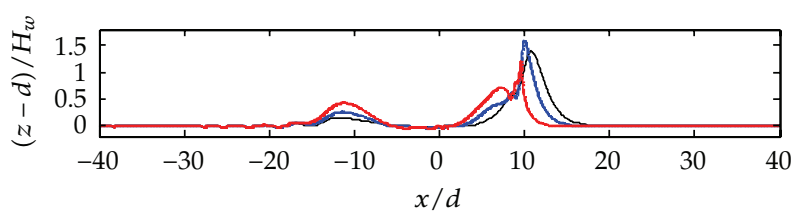

(e)

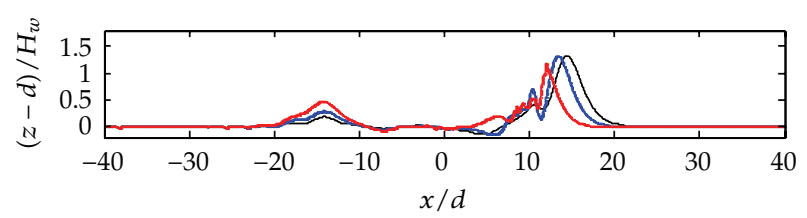

(f)

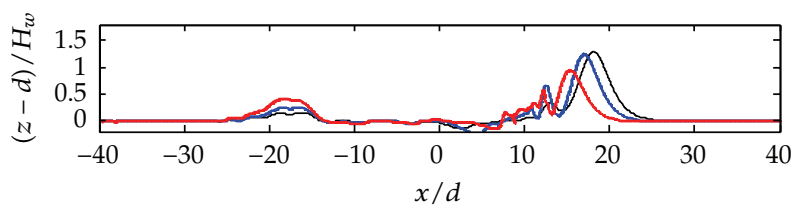

(g)

Figure 4: The effect of breakwater height on wave transformation for $h=2.0 \mathrm{~m}$ black curve, $h=3.0 \mathrm{~m}$ blue curve, and $h=4.0 \mathrm{~m}$ red curve. 


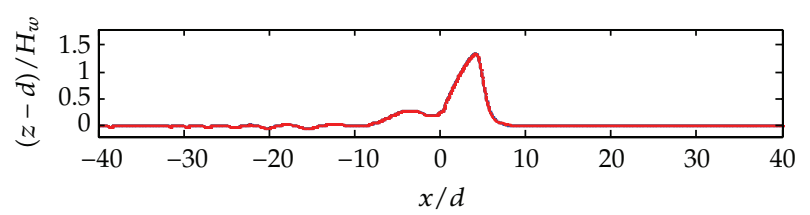

(a)

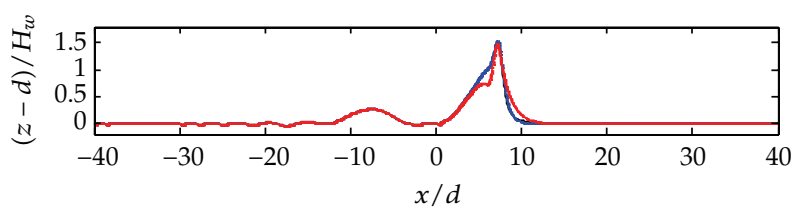

(b)

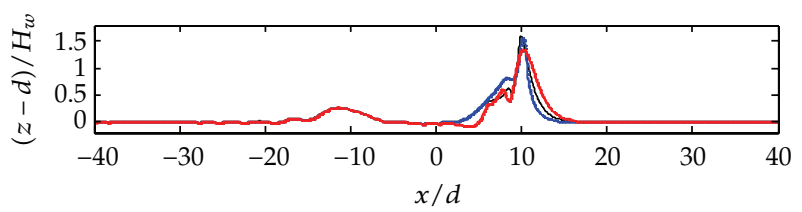

(c)

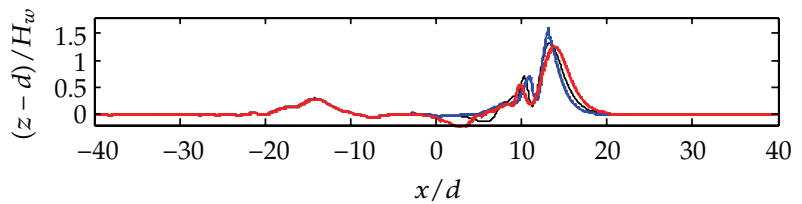

(d)

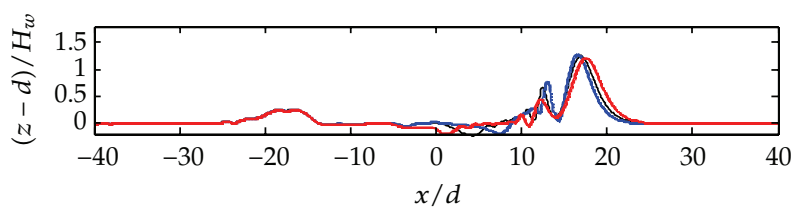

(e)

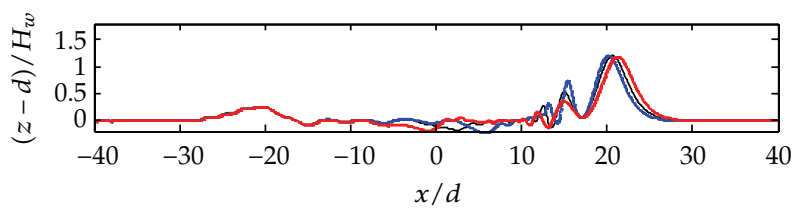

(f)

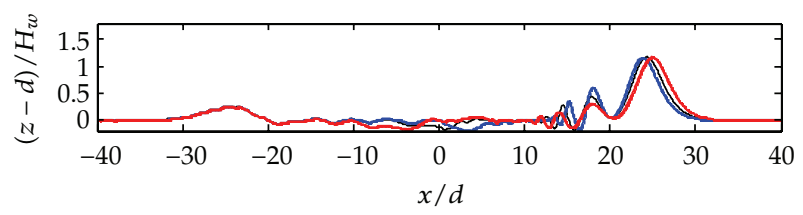

(g)

Figure 5: The effect of breakwater width on wave transformation for $w=50.0 \mathrm{~m}$ black curve, $w=40.0 \mathrm{~m}$ blue curve, and $w=30.0 \mathrm{~m}$ red curve. 

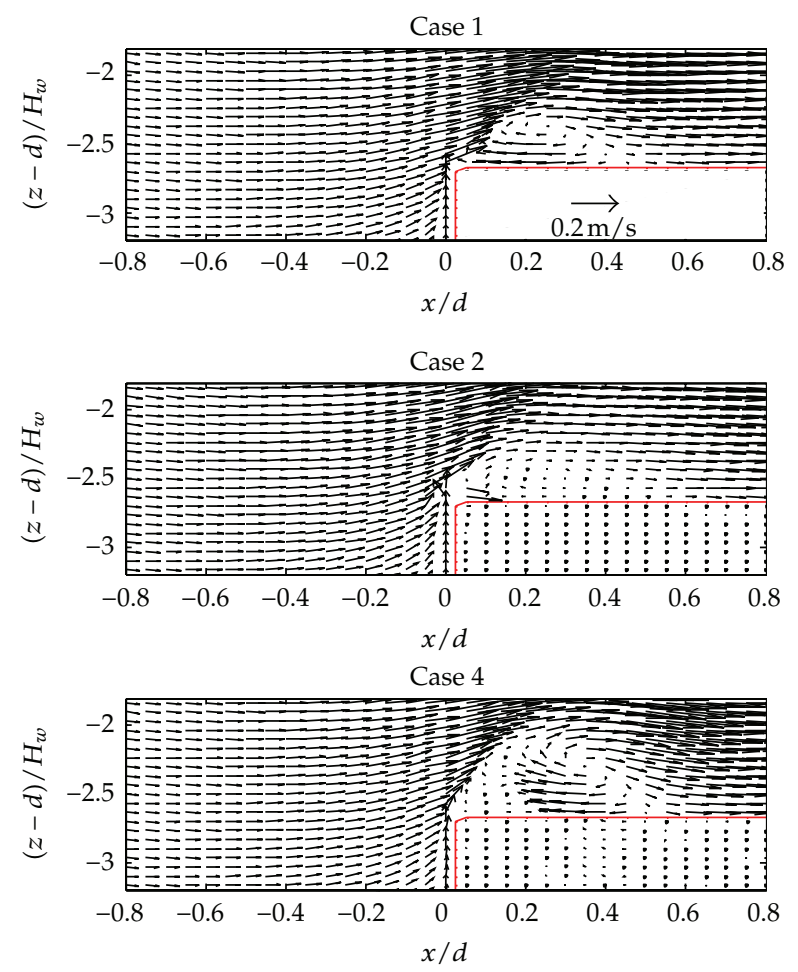

Figure 6: Velocity field at $t(g / d)^{0.5}=49$ as a solitary wave passes over a submerged impervious (Case 1$)$ and two different permeable breakwaters (Cases 2 and 4 ).

The breakwater height varies from $2.0 \mathrm{~m}, 3.0 \mathrm{~m}$ to $4.0 \mathrm{~m}$ for the investigation of the effect of structure height on the wave transformation, and the results are shown in Figure 4. When the wave is approaching the breakwater, the wave distortion is stronger with more energy reflection in the case of higher breakwater (see Figures $4(\mathrm{~b})-4(\mathrm{f})$ ). After interacting with the higher structure, the wave has smaller wave height behind the structure with a lower travelling speed. This is due to more wave energy reflection back to the sea and larger energy dissipation inside the higher structure. To understand the effect of structure width on wave-structure interaction, three different breakwater widths $(w=50.0 \mathrm{~m}, w=40.0 \mathrm{~m}$, and $w=30.0 \mathrm{~m}$ ) are studied. Before the wave reaches the structure (right-hand-side) end, the influence of structure width cannot be identified (see Figure 5(a)). After the wave propagates over the breakwater with longer width, the wave travelling speed is obviously reduced with more wave energy dissipated inside porous structure (see Figures $5(\mathrm{c})-5(\mathrm{~g})$ ).

\subsection{Impact on Velocity Field}

One of the advantages of solving the extended NS-type equations for the outer and inner flow of the permeable structure is that the obtained flow field is much closer to the actual flow field. The velocity filed from VARANS model is used to investigate the effects of porosity and equivalent mean diameter. Figure 6 shows the velocity fields at $t(g / d)^{0.5}=49$ as a solitary wave passes over a submerged impervious (Case 1) and two different permeable breakwaters (Cases 2 and 4). The circulation region due to flow 

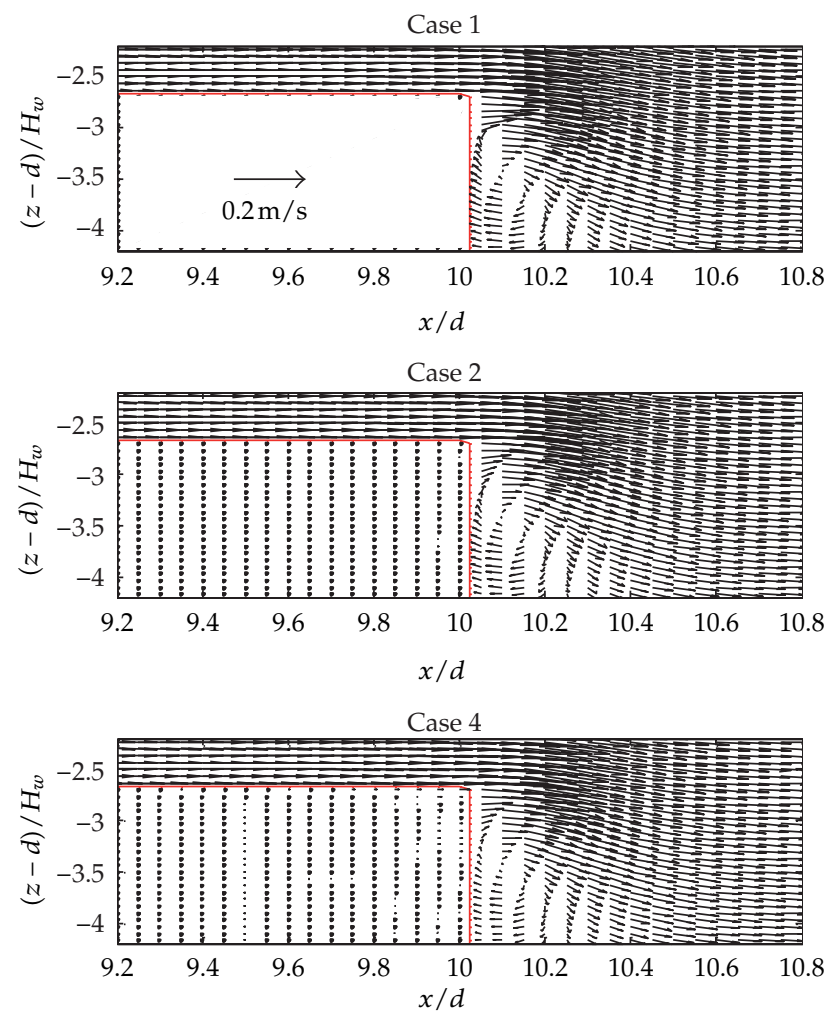

Figure 7: Velocity field at $t(g / d)^{0.5}=59.5$ as a solitary wave passes over a submerged impervious (Case 1$)$ and two different permeable breakwaters (Cases 2 and 4 ).

separation above the left upper-corner of impervious breakwater significantly enlarges in the case of permeable structure. The porous structure allows the wave to travel through, and it consequently provides more space for the vortex development. Larger vortex region occupies for Case 4 in which more porous space is available. While the solitary wave is passing over the porous breakwater, additional wave energy is dissipated due to the friction of porous media. As one can expect, stronger solitary wave-structure interaction leads to more wave energy dissipated. While the solitary wave is leaving the permeable breakwater, the circulation size of wave-induced vortex in the lee side of structure slightly depends on the structural porosity (see Figure 7). However, the higher flow velocity can be seen around the right upper-corner of structure with less porosity. The results also show that flow structure does not change obviously when the equivalent mean diameter $D_{50}$ varies.

Figures 8 and 9 show the effect of breakwater height on the flow velocity field at time $t(g / d)^{0.5}=49$ and $t(g / d)^{0.5}=59.5$, respectively. It can be seen from Figure 8 that the velocity field around breakwater head with a large height differs significantly from those with a small height. A strong flow vortex can be clearly identified in the case with $h=3.0 \mathrm{~m}$ and $h=2.0 \mathrm{~m}$. In the case with $h=4.0 \mathrm{~m}$, the flow vortex is very weak at this time $t(g / d)^{0.5}=49$, mainly due to the space limitation above the breakwater. As indicated by the Figures 8 and 9 , the velocity magnitude is obviously larger in the case of breakwater with a smaller height. The effect of structure width on velocity field is also investigated. The numerical results indicate 

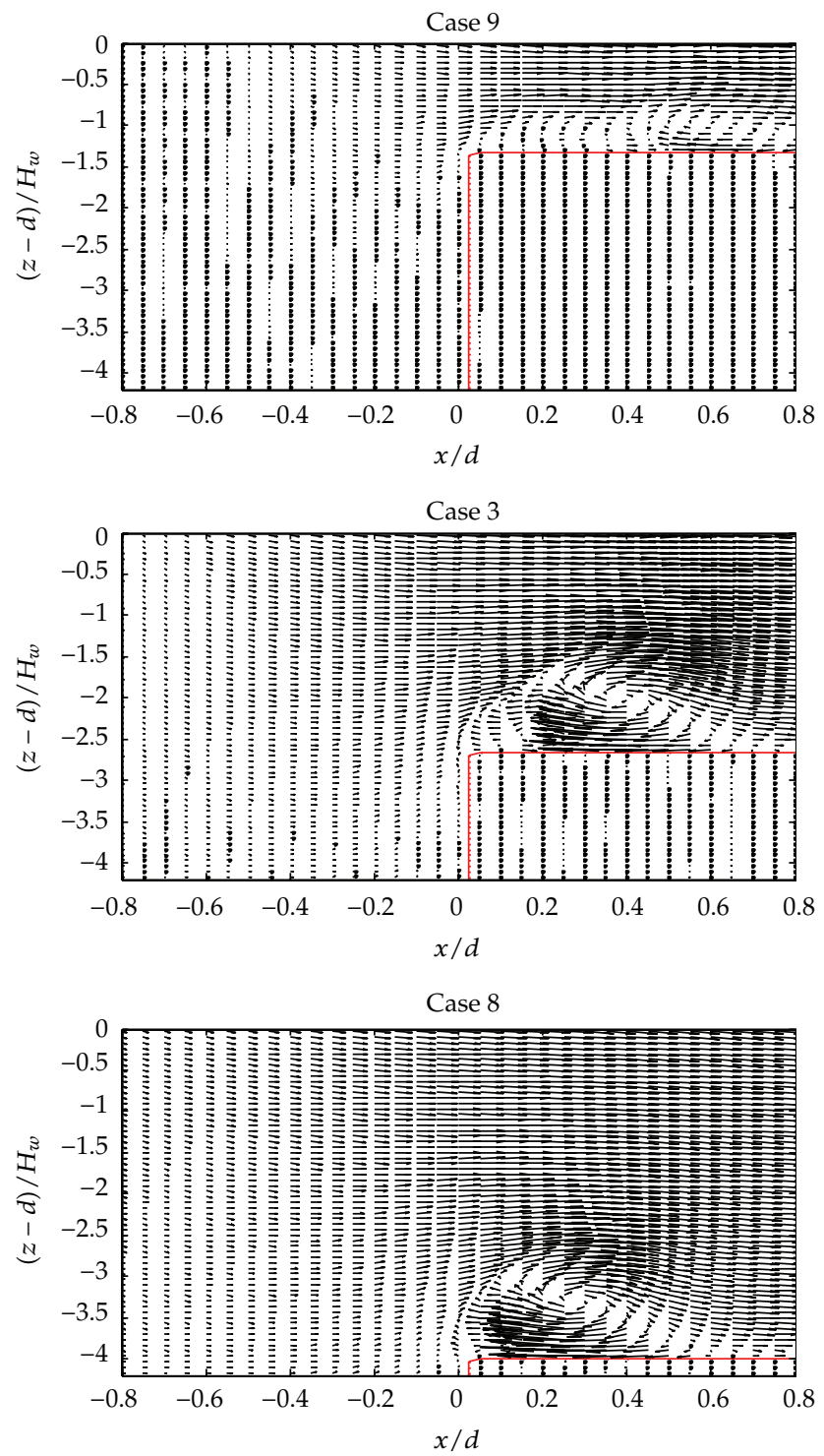

Figure 8: Velocity field at $t(g / d)^{0.5}=49$ as a solitary wave passes over a submerged breakwater with different height $h=4.0 \mathrm{~m}$ (Case 9), $h=3.0 \mathrm{~m}$ (Cases 3), and $h=2.0 \mathrm{~m}$ and (Case 8).

that the flow velocity distribution around structure when wave approaching or leaving the breakwater is very similar in the cases with different structure width.

\section{Conclusions}

In this study, the flow motion around a permeable submerged breakwater has been numerically investigated by applying a numerical VARANS model. This model is used to study the effects of porosity, equivalent mean diameter, structure height, and width on the wave transformation and velocity field in the vicinity of permeable breakwater. Numerical 

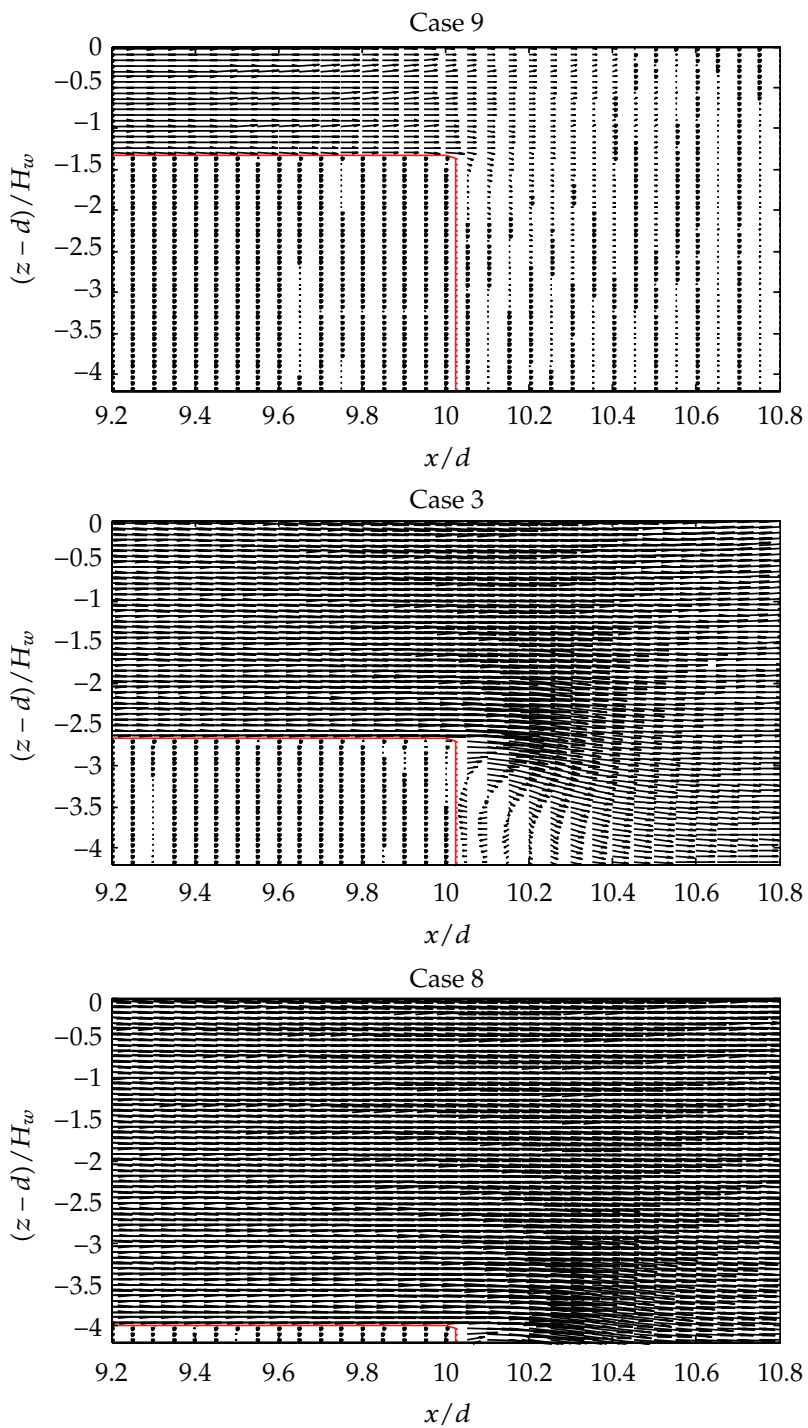

Figure 9: Velocity field at $t(g / d)^{0.5}=59.5$ as a solitary wave passes over a submerged breakwater with different height $h=4.0 \mathrm{~m}$ (Case 9), $h=3.0 \mathrm{~m}$ (Cases 3), and $h=2.0 \mathrm{~m}$ and (Case 8).

results show that structural porosity has an important impact on wave transformation and velocity distribution adjacent. Permeable breakwater provides additional porous space where wave flow travels through and wave energy is dissipated. In contrast, the equivalent mean diameter slightly affects the wave propagation and velocity field although it may increase the permeability of the porous structure. After interacting with the higher structure, the wave has smaller wave height behind the structure with a lower travelling speed. When the wave propagates over the breakwater with longer width, the wave travelling speed is obviously reduced with more wave energy dissipated inside porous structure. 


\section{Acknowledgments}

The authors are grateful for the support from the National Natural Science Foundation of China Grants 51209083, 51137002, and 41176073, the Natural Science Foundation of Jiangsu Province (China) Grant BK 2011026, and the Engineering and Physical Sciences Research Council (UK) Grant no. EP/G006482/1.

\section{References}

[1] Y. S. Cho, J. I. Lee, and Y. T. Kim, "Experimental study of strong reflection of regular water waves over submerged breakwaters in tandem," Ocean Engineering, vol. 31, no. 10, pp. 1325-1335, 2004.

[2] H. B. Chen, C. P. Tsai, and J. R. Chiu, "Wave reflection from vertical breakwater with porous structure," Ocean Engineering, vol. 33, no. 13, pp. 1705-1717, 2006.

[3] J. L. Lara, I. J. Losada, and R. Guanche, "Wave interaction with low-mound breakwaters using a RANS model," Ocean Engineering, vol. 35, no. 13, pp. 1388-1400, 2008.

[4] D.-S. Hur, W.-D. Lee, and W.-C. Cho, "Characteristics of wave run-up height on a sandy beach behind dual-submerged breakwaters," Ocean Engineering, vol. 45, pp. 38-55, 2012.

[5] C. J. Huang, H. H. Chang, and H. H. Hwung, "Structural permeability effects on the interaction of a solitary wave and a submerged breakwater," Coastal Engineering, vol. 49, no. 1-2, pp. 1-24, 2003.

[6] C. L. Ting, M. C. Lin, and C. Y. Cheng, "Porosity effects on non-breaking surface waves over permeable submerged breakwaters," Coastal Engineering, vol. 50, no. 4, pp. 213-224, 2004.

[7] L. H. Huang and H. I. Chao, "Reflection and transmission of water wave by porous breakwater," Journal of Waterway, Port, Coastal, and Ocean Engineering, vol. 118, no. 5, pp. 437-452, 1992.

[8] I. J. Losada, M. D. Patterson, and M. A. Losada, "Harmonic generation past a submerged porous step," Coastal Engineering, vol. 31, no. 1-4, pp. 281-304, 1997.

[9] N. Kobayashi, L. E. Meigs, T. Ota, and J. A. Melby, "Irregular breaking wave transmission over submerged porous breakwater," Journal of Waterway, Port, Coastal and Ocean Engineering, vol. 133, no. 2, pp. 104-116, 2007.

[10] I. J. Losada, J. L. Lara, R. Guanche, and J. M. Gonzalez-Ondina, "Numerical analysis of wave overtopping of rubble mound breakwaters," Coastal Engineering, vol. 55, no. 1, pp. 47-62, 2008.

[11] A. S. Koraim, E. M. Heikal, and O. S. Rageh, "Hydrodynamic characteristics of double permeable breakwater under regular waves," Marine Structures, vol. 24, no. 4, pp. 503-527, 2011.

[12] A. Nakayama and F. Kuwahara, "Macroscopic turbulence model for flow in a porous medium," Journal of Fluids Engineering, Transactions of the ASME, vol. 121, no. 2, pp. 427-433, 1999.

[13] P. L.-F. Liu, P. Lin, K. A. Chang, and T. Sakakiyama, "Numerical modeling of wave interaction with porous structures," Journal of Waterway, Port, Coastal and Ocean Engineering, vol. 125, no. 6, pp. 322-330, 1999.

[14] M. H. J. Pedras and M. J. S. de Lemos, "Macroscopic turbulence modeling for incompressible flow through undefromable porous media," International Journal of Heat and Mass Transfer, vol. 44, no. 6, pp. 1081-1093, 2001.

[15] T.-J. Hsu, T. Sakakiyama, and P. L.-F. Liu, "A numerical model for wave motions and turbulence flows in front of a composite breakwater," Coastal Engineering, vol. 46, no. 1, pp. 25-50, 2002.

[16] M. Chandesris, G. Serre, and P. Sagaut, "A macroscopic turbulence model for flow in porous media suited for channel, pipe and rod bundle flows," International Journal of Heat and Mass Transfer, vol. 49, no. 15-16, pp. 2739-2750, 2006.

[17] M. F. Karim, K. Tanimoto, and P. D. Hieu, "Modelling and simulation of wave transformation in porous structures using VOF based two-phase flow model," Applied Mathematical Modelling, vol. 33, no. 1, pp. 343-360, 2009.

[18] F. J. Mendez, I. J. Losada, and M. A. Losada, "Wave-induced mean magnitudes in permeable submerged breakwaters," Journal of Waterway, Port, Coastal and Ocean Engineering, vol. 127, no. 1, pp. 7-15, 2001.

[19] M. R. A. van Gent, "The modelling of wave action on and in coastal structures," Coastal Engineering, vol. 22, no. 3-4, pp. 311-339, 1994.

[20] E. C. Cruz, M. Isobe, and A. Watanabe, "Boussinesq equations for wave transformation on porous beds," Coastal Engineering, vol. 30, no. 1-2, pp. 125-156, 1997. 
[21] J. L. Lara, I. J. Losada, M. Maza, and R. Guanche, "Breaking solitary wave evolution over a porous underwater step," Coastal Engineering, vol. 58, no. 9, pp. 837-850, 2011.

[22] P. Lin and P. L.-F. Liu, "Internal wave-maker for Navier-Stokes equations models," Journal of Waterway, Port, Coastal and Ocean Engineering, vol. 125, no. 4, pp. 207-215, 1999.

[23] P. Lin and P. L.-F. Liu, "A numerical study of breaking waves in the surf zone," Journal of Fluid Mechanics, vol. 359, pp. 239-264, 1998.

[24] C. W. Hirt and B. D. Nichols, "Volume of fluid (VOF) method for the dynamics of free boundaries," Journal of Computational Physics, vol. 39, no. 1, pp. 201-225, 1981.

[25] W. J. Rider and D. B. Kothe, "Reconstructing volume tracking," Journal of Computational Physics, vol. 141, no. 2, pp. 112-152, 1998. 


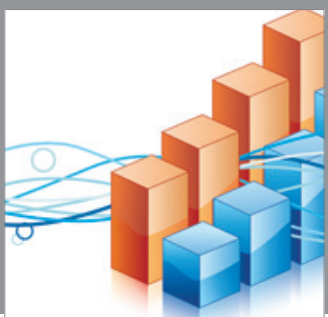

Advances in

Operations Research

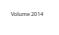

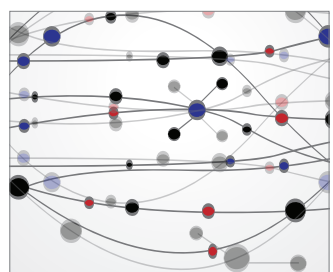

\section{The Scientific} World Journal
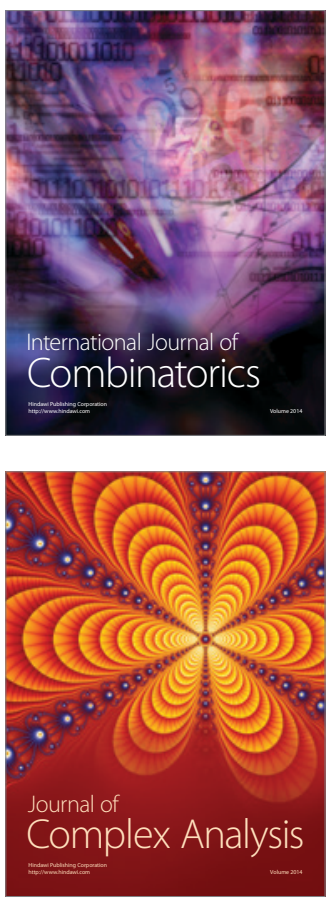

International Journal of

Mathematics and

Mathematical

Sciences
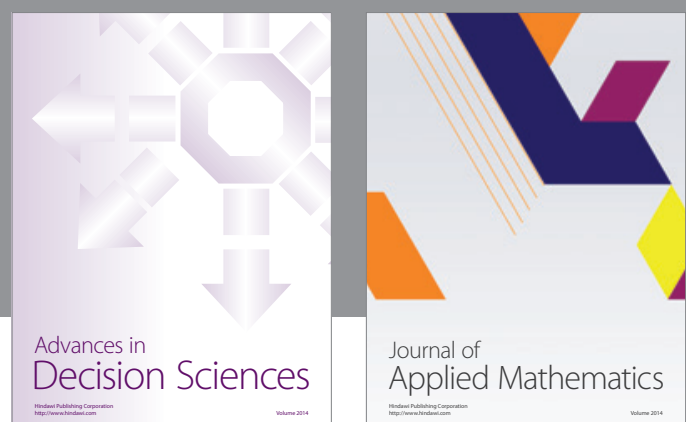

Journal of

Applied Mathematics
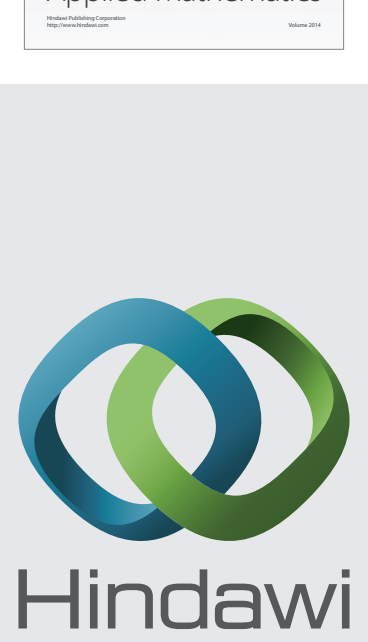

Submit your manuscripts at http://www.hindawi.com
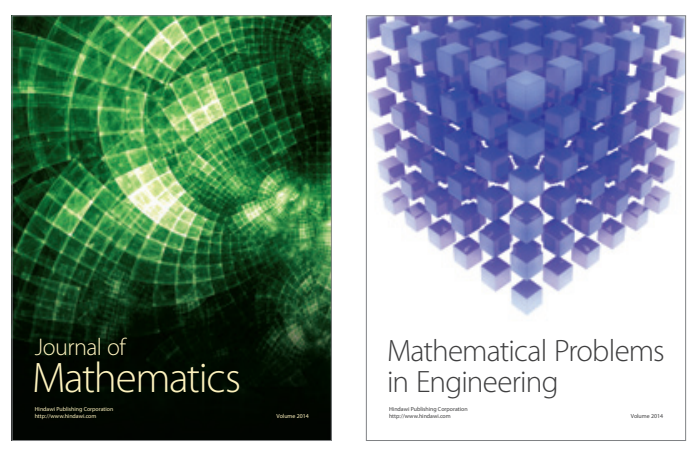

Mathematical Problems in Engineering
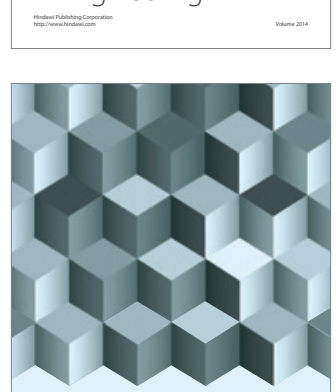

Journal of

Function Spaces
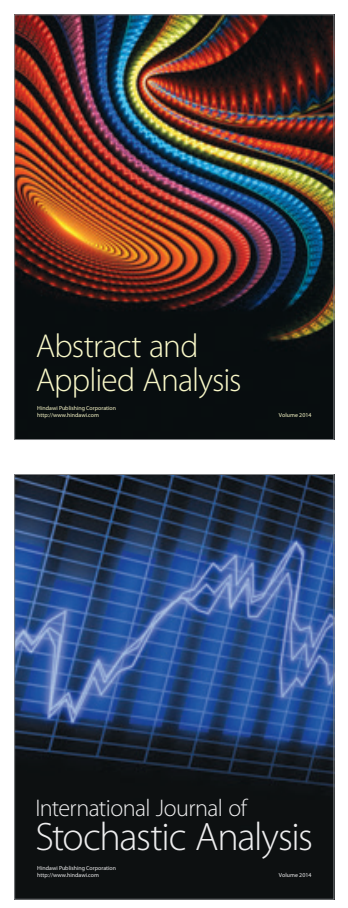

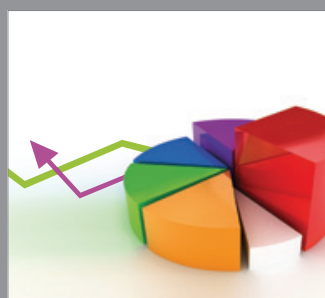

ournal of

Probability and Statistics

Promensencen
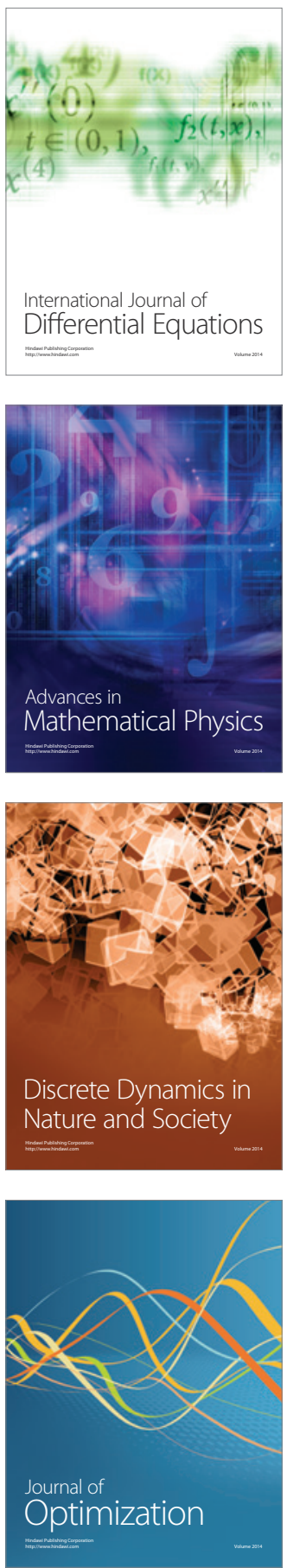